\title{
Accessibility and Visibility Analysis of Moinhos de Vento Park in Porto Alegre, Rio Grande do Sul, Brazil
}

\author{
Vanessa Casarin, Renato T. de Saboya and Alina Gonçalves Santiago \\ Post-graduation Program in Architecture and Urban Planning (PosARQ), Universidade Federal de Santa Catarina (UFSC), \\ Florianópolis 88040-970, Brazil
}

\begin{abstract}
This paper analyzes physical and visual accessibility at Moinhos de Vento Park in Porto Alegre, Rio Grande do Sul, Brazil, through Space Syntax methods. The Park presents a particularity in its configuration: it is crossed by an important avenue in the city that splits it in two portions linked by an elevated pedestrian path. The two portions of the park have different accessibility degrees and intensity of use due to - we believed — the way they are inserted in the urban pattern. Both the barrier caused by the avenue crossing the park and the differences of connectedness of each portion to its surrounding grid result in the level of integration occurring in different ways, turning the east portion less intensely used. The all-line and visibility integration maps showed that this was the case, and confirmed that spatial configuration plays an important role in rendering the east portion less integrated and in explaining the more intense use of the west portion. Integration maps showed that the most integrated areas are indeed the most used ones, although line and visibility integration differed slightly as to the exact location. This difference was probably due to the way barriers were modeled, since permeability took into account the paths while visibility considered all the ground as a whole, provided there were no barriers to sight. Another explanation for the difference is the lake located at the center of the west portion which contributed to this location's visual integration but, on the other hand, displaced line integration to the larger convex space to the north.
\end{abstract}

Key words: Accessibility, visibility, integration, space syntax, urban morphology.

\section{Introduction}

The present paper analyzes the level of integration at Moinhos de Vento Park in Porto Alegre, Rio Grande do Sul, Brazil, through space syntax methods. Moinhos de Vento Park, "Parcão" as it is known by local people, presents a particularity in its spatial configuration: it is crossed by an important road, Goethe Avenue, that splits it in two portions linked by an elevated pedestrian path. Although the two portions of the park have pedestrian accessibility through this main avenue, it occurs in different ways in each one of them due to their distinct connectivities to the surrounding urban grid. It is believed that both of these particularities result in different levels of integration for each one, with the additional effect of making it not to be perceived as a whole by users, who tend to think of the west portion as a completely independent part.

Corresponding author: Vanessa Casarin, $\mathrm{PhD}$ student, research field: landscape and urban design. E-mail: vanessa.arq@gmail.com.
At this stage of the research we measured the level of integration and visibility offered by the spatial configuration of the area. We suggest, in a second stage of research, interviews with users to verify if the results yielded by space syntax are corroborated in terms of spatial cognition.

We hope that this analysis of spatial configuration in urban parks may aid the design of spaces more integrated to its surroundings, therefore fostering spaces with higher probability of being intensely used and appropriated by the population.

\section{Theoretical Approach}

\subsection{Accessibility and the Configuration of Urban Spaces}

The understanding of multiple relationships which conform the urban structure and their interrelations to components from natural environment, and the responses from urban design to attend users' needs 
regarding the spatial characteristics of urban environments are some of the elements with which the landscape and urban design professionals face when building the city.

The articulation of the urban grid, integration between public spaces, architecture and landscape, harmony to climate and environmental characteristics, the response to necessities of space and use, the quality of accessibility to space and the reduction of physical and visual barriers are some of the most relevant aspects in the design of successful urban public spaces [1].

Accessibility can be considered as a prior condition to the appropriation and use of a space [1, 2], for obvious reasons. Furthermore, accessible public spaces allow proper cognition of environmental cues, possibility to move through it, usage of space for varied activities and execution of activities with autonomy, comfort and security.

Carr [2] points out three major components of accessibility: physical, visual and symbolic access. To be physically accessible, a space has to be free of physical barriers (such as fences, for example, which are becoming common in Brazilian cities), but not only that: it should also be well connected in terms of paths and circulation. We also can have some degrees of physical access in a space according to the number of entrances to it.

The visual access or visibility is important in order to make people feel free to enter a space [2]. Visibility is also important so people can estimate whether it is safe to enter a space, or if they would be welcome in it. In general terms, the more visible a space is, the more likely it is to be perceived as a public space (which is not the same as saying that it will in fact be used and appropriated by citizens). Concerning the visual access, there can also be degrees of access defined by the way barriers are established, how much they show or hide, what can be seen from particular points, and so on. Another important feature of visibility accessibility is that it can be used to shape architectural space, creating differentiations among elements regarding to hierarchy, imageability and legibility [3].

The symbolic access, the third one identified by Carr [2], involves the existence of cues which can be given by the presence of other people or design elements, suggesting who is and who is not welcome to that space. An example of human factors in social-symbolic access is the gatekeepers in nonhuman factors we can identify the presence of shops or restaurants, with their related spaces for sitting or walking that welcome people.

Some barriers in a setting can define a space belonging to a particular group. Carr [2] argues that these environmental barriers, which can include limited entrance points and visibility, may be considered alternatives to the presence of security guards. This property of barriers is of special importance to architectural space. Through it space can be shaped, and meaning can be conveyed. This is one of the most important features of architecture and urban design and, as we can see, visibility and accessibility play an important role in it. Therefore, in our study we chose an analysis method that can account for these properties of space, as we describe next.

\subsection{Space Syntax Foundations}

Space syntax was conceived in the 1970s and had its origins on the observation that space is the common ground for the physical and social aspects of cities and, therefore, all social activity leaves spatial traces in the form of urban patterns [4-6]. Spatial configuration, or pattern, is one of the main concepts with which space syntax works. If it can be somehow described and analyzed, then it could be possible to trace forces of influence between spatial features and social factors.

In this context, spatial configuration is concerned with relations between spaces which take into account the relations to the various spaces of a system. One of the main contributions of space syntax is the description of open public spaces in a way that spatial 
configuration can be apprehended, and a set of derived measures that take into account the relations of every space to all others in a system. These measures are mainly formal interpretations of the notion of spatial integration and segregation given in a measurable scale, which in turn allow statistical comparison of different spatial forms and estimation of their degree of association with different cultural traits.

The units of representation are derived from the way people use space, be it moving through it, interacting with other people or even just seeing the space from one particular point $[6,7]$. The first two activities suggest linear and convex descriptions, respectively, while the third one can be understood as the visual field encompassing all locations visible from a particular point in space, also known as isovists [8]. Turner advanced the use of isovists by devising ways of obtaining configurational measures from them, as opposed to the purely local measures used in previous studies. Therefore, visibility can be analyzed through visibility graphs and measures of visual integration and clustering [8].

\subsubsection{Axial Representation of Open Spaces}

The axial map of a urban grid, on the other hand, accounts for the description of movement-related aspects of urban form and is defined by Hillier et al. [9] as the set of "longest and fewest straight lines that can be drawn through the spaces of the grid so that the grid is covered. "Covered" means that all rings of circulation are complete and all convex elements passed through". The map is transformed into a matrix representation, where each axial line is numbered, and an incidence matrix is compiled of connectivity between lines (a line is said to be connected when it crosses or intersects another line).

The graph allows a number of measures that can be used to describe configurational properties of the grid, related to connectivity, depth, accessibility and control. The most integrated lines are those which tend to be more accessible in the urban grid, and usually correspond to main paths or shopping areas.
Segregated lines, on the other hand, are generally related to more quiet residential areas that tend to be deeper structures in the overall urban grid.

The all line map was introduced by Hillier [10] in order to allow spatial analysis on a finer scale, and is aimed at representing all possible lines of sight and movement in a given space. This set of all lines is then modified by the placement of objects that intercept some of them and thus create differentiation in the resulting pattern of lines. For practical purposes, since there is no limit to the number of all possible lines, the map includes all lines that are tangent to the vertices of objects (for more details, see [10]).The integration and other space syntax measures are then applied to these lines in much the same way as to conventional axial maps.

\section{Methods}

The methodology adopted in this analysis included data collection of physical aspects, in situ observations and the posterior application of space syntax methods. The software used was Depthmap, developed by Alasdair Turner.

For the space syntax analysis three maps were modeled in CAD (Computer Aided Design). The first considered physical accessibility and was subjected to all-line integration analysis. Another map was built considering visual accessibility, and both visual connectivity and integration were derived from it. The third original CAD map is in fact a scenario, through which an alternative configuration was tested in order to evaluate the possibility of stitching the two portions of the park together, in a way that spatial integration could be more evenly distributed.

The elevated passage posed a special problem, since we had to model the system of barriers in such a way as to reproduce the lack of connectivity between Goethe Avenue and the passage. So, all line maps were built normally and, subsequently, the connections between these two spaces were unlinked in Depthmap. 
Based on these four generated maps, we analyzed the spatial configuration of the park and the way it is inserted in the urban fabric, trying to identify those aspects that more directly influence the way the park is perceived and used by the population.

\section{Some Abstract Experiments}

We present next a series of schematic maps from which we draw some conclusions that will be useful in the analysis of the real case studied below. These maps are basic first-order visibility graphs [8], which we believe to be a kind of analysis whose usefulness to architectural studies is currently underrated. One of the motives for this is that visibility graphs are usually treated as visibility "from", as in "how many points can be seen from X?", nevertheless, visibility “to” is as important as visibility "from”, at least for architectural space, since it gives a good estimate about spaces with high visual prominence and, therefore, with potential to have high imagination [3] and an important role in space cognition and legibility. Knowing "how many points can see $X$ " can also be used to assess its hierarchy in a given spatial configuration.

The first obvious conclusion drawn from these maps concerns the importance of intersections in terms of visibility. In all of them these locations tend to be more visually prominent than others, which derives from the fact that intersections can be seen from more than one direction (Figs. 1-2). This is a long known phenomenon to urban designers, which have been using intersections to place their most significant buildings, as have been doing retailers in search of the most favorable spots for their businesses.

Figs. 3 show a variation in the size of visual barriers, which could be buildings or dense vegetation and their effects on the visibility graph. These barriers can create great differences between open spaces and the surrounding streets, and their configuration can change the location of higher visibility spots in the larger open space. They clearly show the importance of non-tangent streets that have the potential of creating long lines of sight straight to the center of the "plaza”, thus connecting it visually to a large portion of the urban grid and affording a richer set of possibilities to be explored in order to create architectural complexity and variety.

Fig. 4 shows the importance of visual connectivity to the overall distribution of visibility, a notion that will be particularly relevant to our case study. A small opening in the central barrier yields significant change in the visibility status of the west side of the plaza.

Another interesting finding can be seen in Fig. 5. The placement of a barrier in an otherwise free space (such as the one in Fig. 1) can contribute to highlight the element that act as a barrier, but at the cost of rendering its immediate surrounding less visible. A quick look at Fig. 5 could give the impression that the circle is in a less visible area, but in fact it acts as a barrier to its immediate vicinity. To evaluate the visibility status of an element, therefore, we have to analyze the distribution of visibility as it is before its placement. In this case, Fig. 1 shows that the central area of the plaza would be a higher visibility spot than the more peripheral one depicted in Fig. 5.

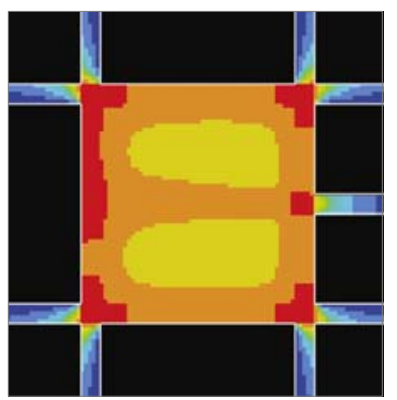

Fig. 1 No visual barriers.

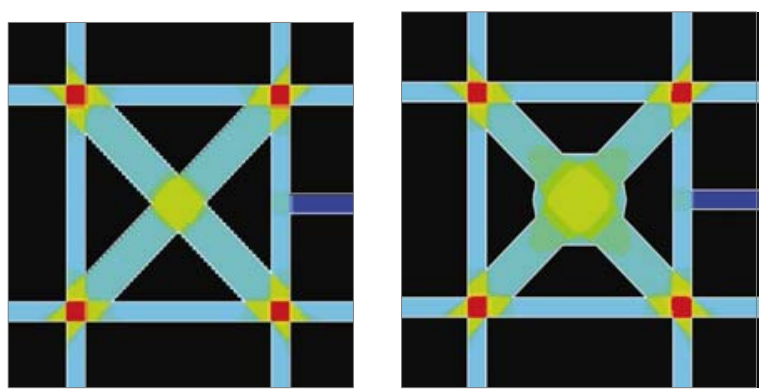

Figs. 2 Visual barriers next to streets/ variation in size in central path. 

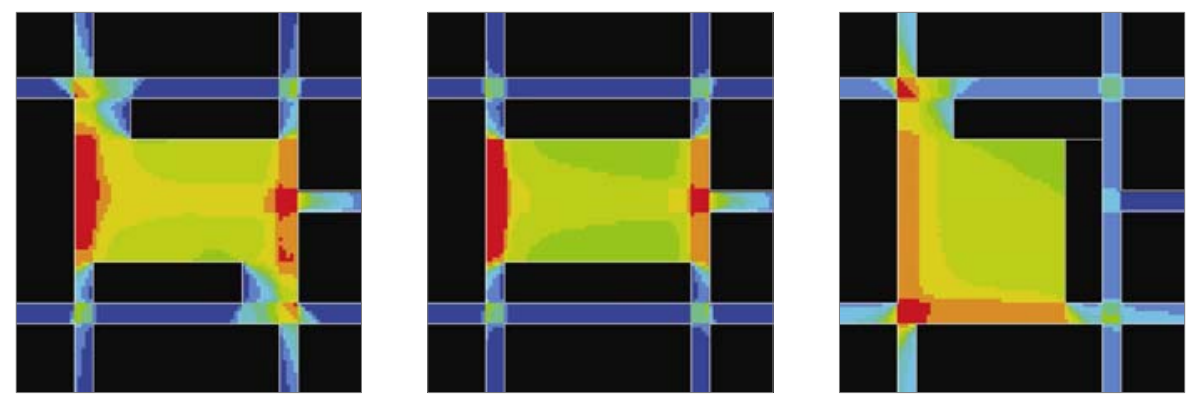

Figs. 3 Variation in size and position of visual barriers next to the streets and in relation to non-tangent street.
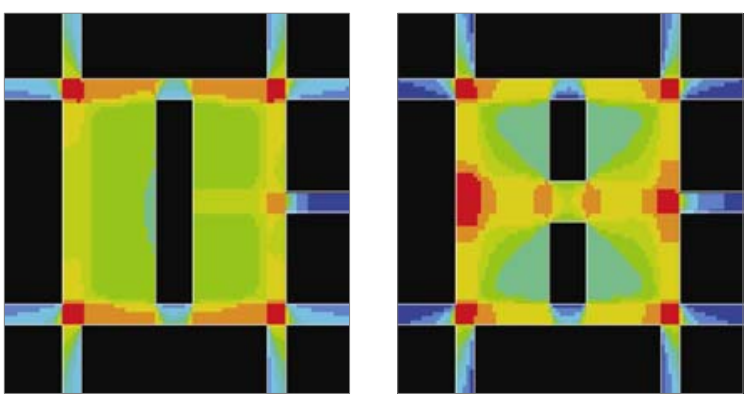

Figs. 4 Variation in configuration of visual barriers in central locations.
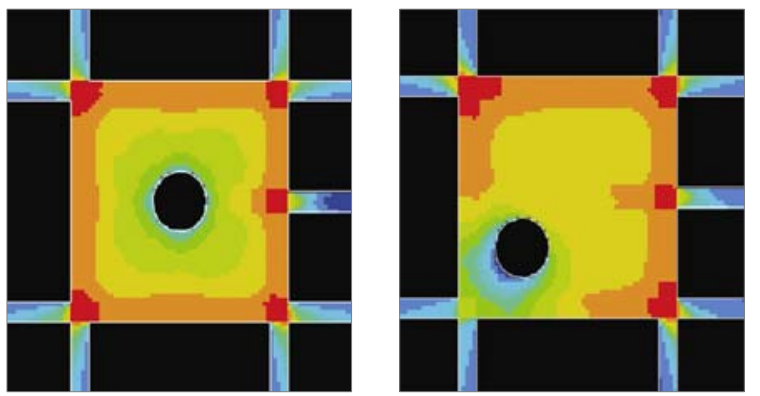

Figs. 5 Variation in form and position of visibility barriers in central locations.

Directly related to that, in a situation where a visibility axis is to be ended by a monument, it must be considered the impact that this configuration will have on everything that is "behind" the monument, now acting as a barrier (depending, of course, on its design). The visibility score will tend to diminish significantly, probably giving that particular location a completely different ambience.

Figs. 3 and 4 show good spots in which to locate especially important buildings, such as public administration, churches, and so on. They show situations where high visibility is achieved at the mid section of blocks, in addition to those located at the intersections. Locating buildings at these spots can contribute to highlight their symbolic importance.

Fig. 5 shows an example in which the principle of placing monuments in the open space was used in conjunction with the non-tangent axis to intensify the contrast of the high and low visibility areas, thus emphasizing the buildings located at the former ones. The barrier effect of the monument, which could conflict with the intended effect if it was placed right along the axis, can have the opposite consequence, that is, creating less visible areas at the side of the building to achieve a contrast effect.

\section{Case Study: Moinhos de Vento Park, Porto Alegre, RS, Brazil.}

The Moinhos de Vento Park is located on north-downtown Porto Alegre, at Moinhos de Vento District, one of the areas of the city with higher land values. The Park has a total area of 115,000 $\mathrm{m}^{2}$, being crossed by Goethe Avenue and surrounded by Vinte e Quatro de Outubro, Comendador Caminha e Mostardeiro Street (Fig. 6).

The east side of the Park, where the sports sector is located, has one of its edges adjacent to the back side of Quintino Bocaíuva Street's parcels. At the west side of the Park, the most intensely used by the population, other activities take place such as playgrounds for children, the lake and contemplation areas, jogging and leisure. Both sides of the park have car parking and these two sides are connected by an elevated pedestrian path. Usually people do not perceive the sports sector, in the east portion, as a part of the park. 
The park has a slightly rugged topography, with a central lake in the west portion where some leisure activities occur, alternative pedestrian paths next to the lake and Mostardeiro Street with permeable pavement and impermeable decorative pavement next to Vinte e Quatro de Outubro Street. Dense vegetation is present in the borders, next to high speed streets like Goethe Avenue working as acoustic barriers to a more silent atmosphere inside the park (Figs. 8-10).

The park is kept in good condition and is visited by people of all ages every day, it receives a large amount of people during the weekends. Usually people stay on the grass along and around the lake spreading from the center of the park to the direction of Rua Vinte $\mathrm{e}$ Quatro de Outubro (Fig. 7); this is the most intensely used area of the park, mainly on Sunday afternoons. Vinte e Quatro de Outubro Street on the north, and Mostardeiro Street, on the south, are the main accesses to the park, where there is an open and high vegetation that provide physical and visible access.

Some buildings, like the Administration, Library and Public Bathrooms, can also be found at the park.
The immediate surroundings are characterized by mixed use (residential and commercial) with an intense commercial and service sector. There are also some luxury hotels and shops in the neighborhood. Mostardeiro Street, on the other side, has a more residential character.

The spatial configuration of the Park can be seen on the images bellow. The floor plan (Fig. 6) was based on a map made by QUAPA Project from USP (Universidade de São Paulo, SP), dated from Jan. 1995. This plan was verified with local visits to the place by researchers, which also allowed the checking of whether or not existing vegetation should be considered as barriers, both for movement and visibility.

The design of the Park from 1972, was completed in two stages. The first stage was elaborated by the Architect José Morbini, and the second stage, the sports area, by the Architect Ana Maria Godinho Germani [11].

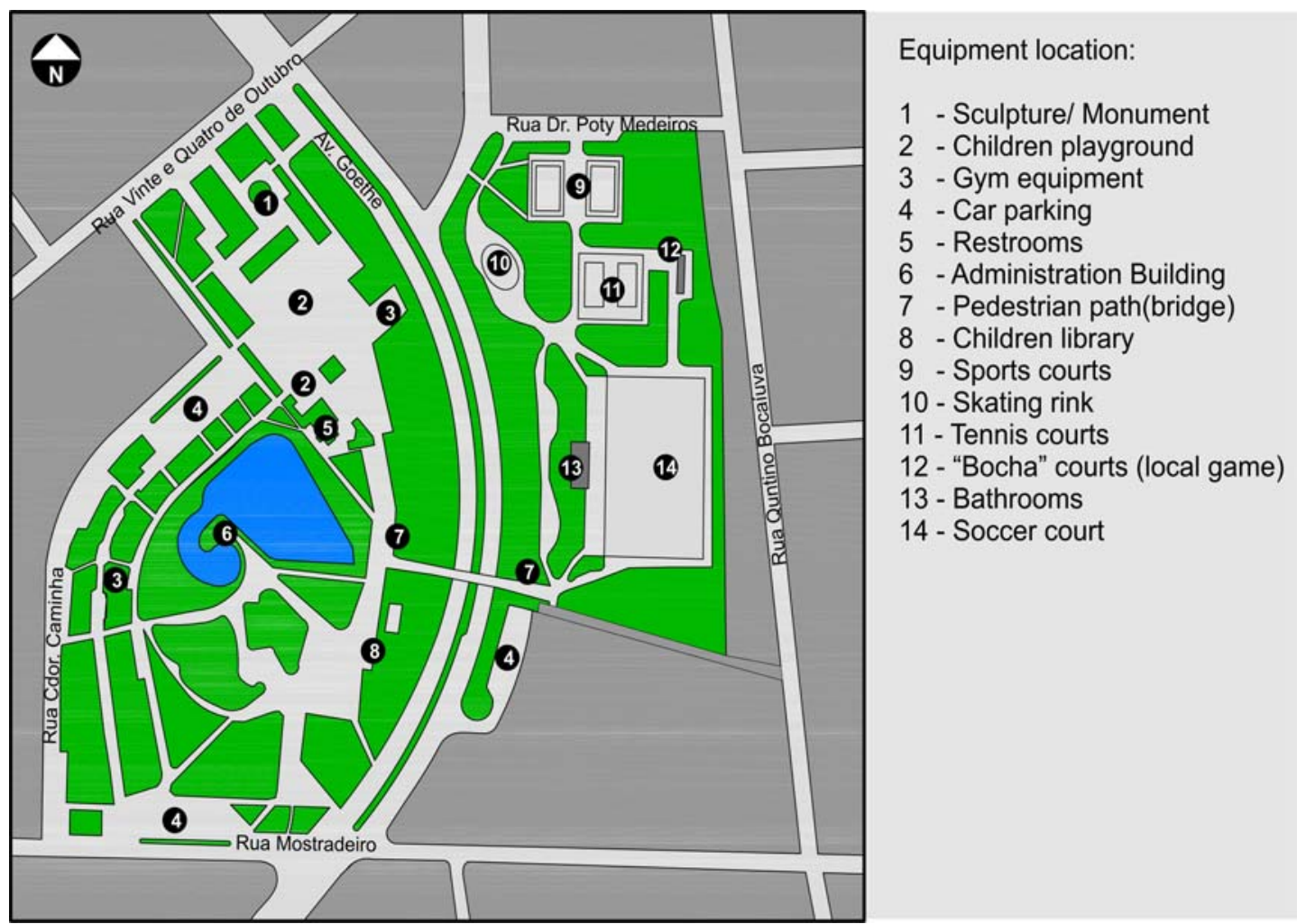

Fig. 6 Floor plan Parque Moinhos de Vento, configuration of paths, Fonte: Quapa/SEL map, Silvio Macedo. 


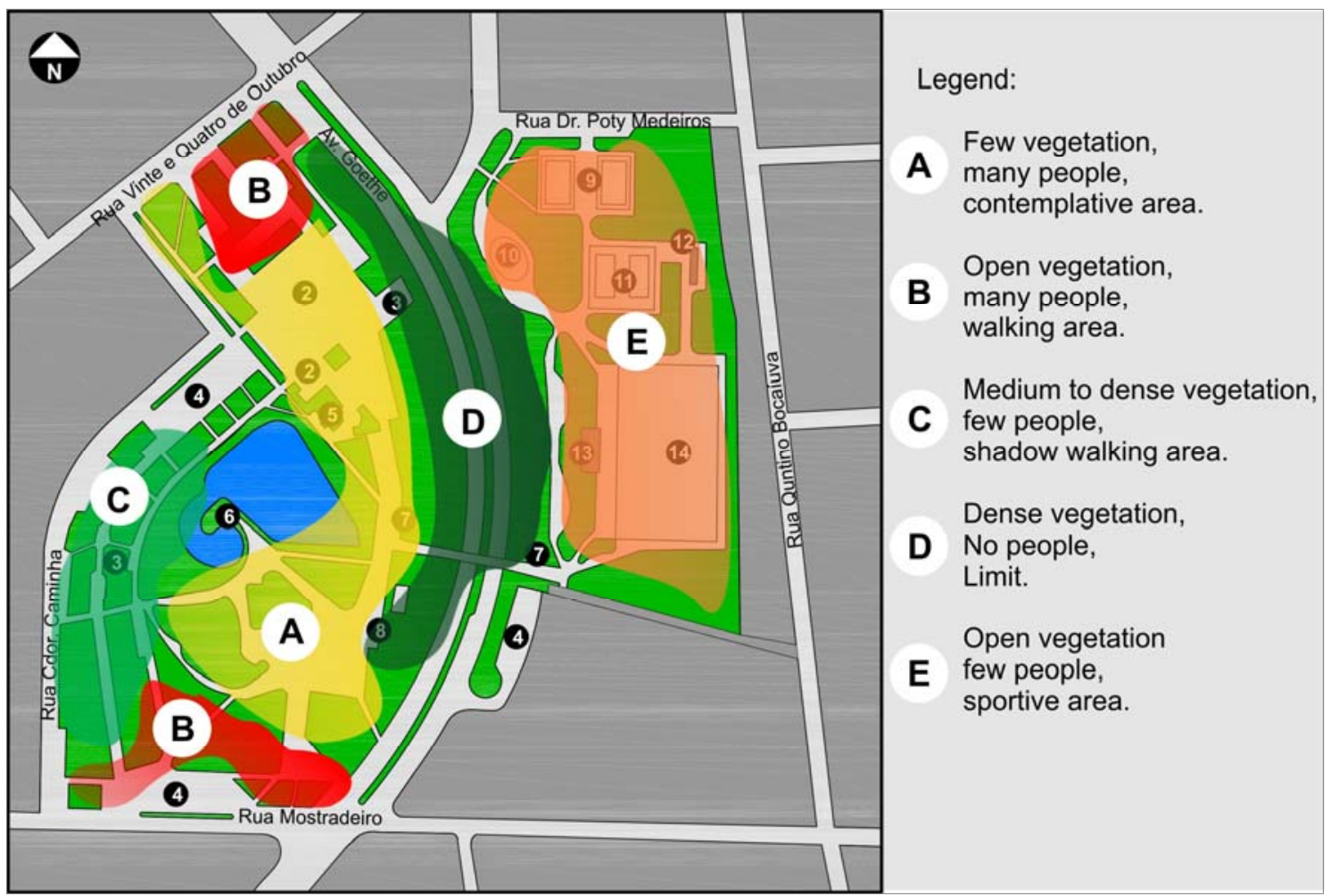

Fig. 7 Floor plan Parque Moinhos de Vento, configuration of paths, adapted from Quapa/SEL map, Silvio Macedo.

The all-line map (Fig. 11) shows that Goethe Avenue works as a barrier to the Park as a whole, rendering the sports area, located at the east portion, segregated from the main (west) portion of the park as well as from the urban grid as a whole. On the other hand, the west portion presents a higher level of integration inside the boundary and in relation to the urban grid. The all-line map also shows that the east portion has a sharp decline in integration values, with a great increase in space depth despite the fact that it is smaller than the other side. This can be explained by the lack of more continuous and long axial lines, resulting in a segmented configuration and irregular grid with many intercepting barriers to movement.

Another remarkable feature of the east portion is the few numbers of connections to its surroundings. Most of its boundaries are blocked by dense vegetation, creating an extremely segregated environment.

Considering the visibility map shown below (Fig. 12), the segregation between the two portions is even more acute. This is due to the dense vegetation around both portions along Goethe Avenue that works as an acoustic barrier to protect internal areas of the park from the loud sound of cars in high speed, but that also acts as a barrier to movement and visibility, creating spaces that are perceived as being distinct from one another.

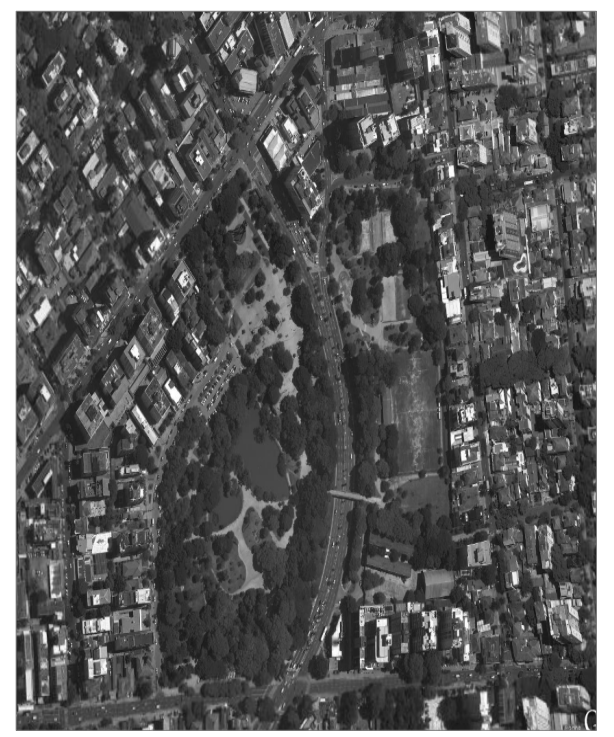

Fig. 8 Satellite Image from Google, vegetation configuration. 


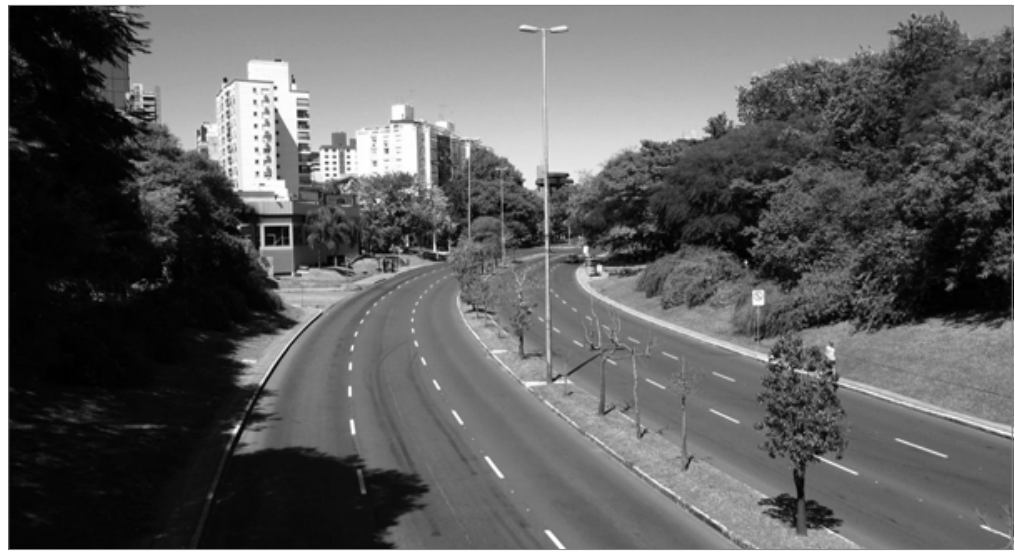

Fig. 9 Av. Goethe, green acoustic and visual barrier (credit: Valery Pugatch).

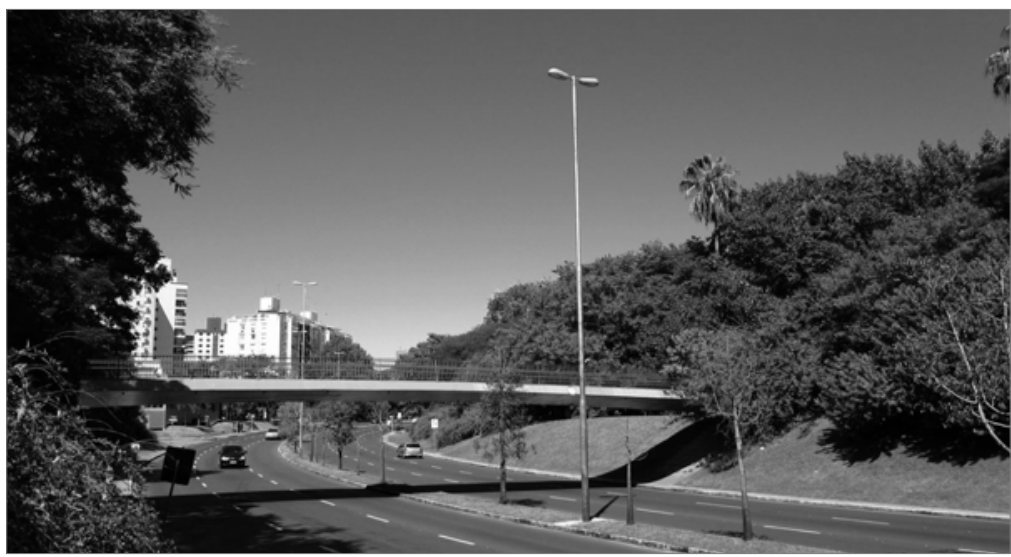

Fig. 10 Elevated passage above Goethe Avenue (credit: Valery Pugatch).

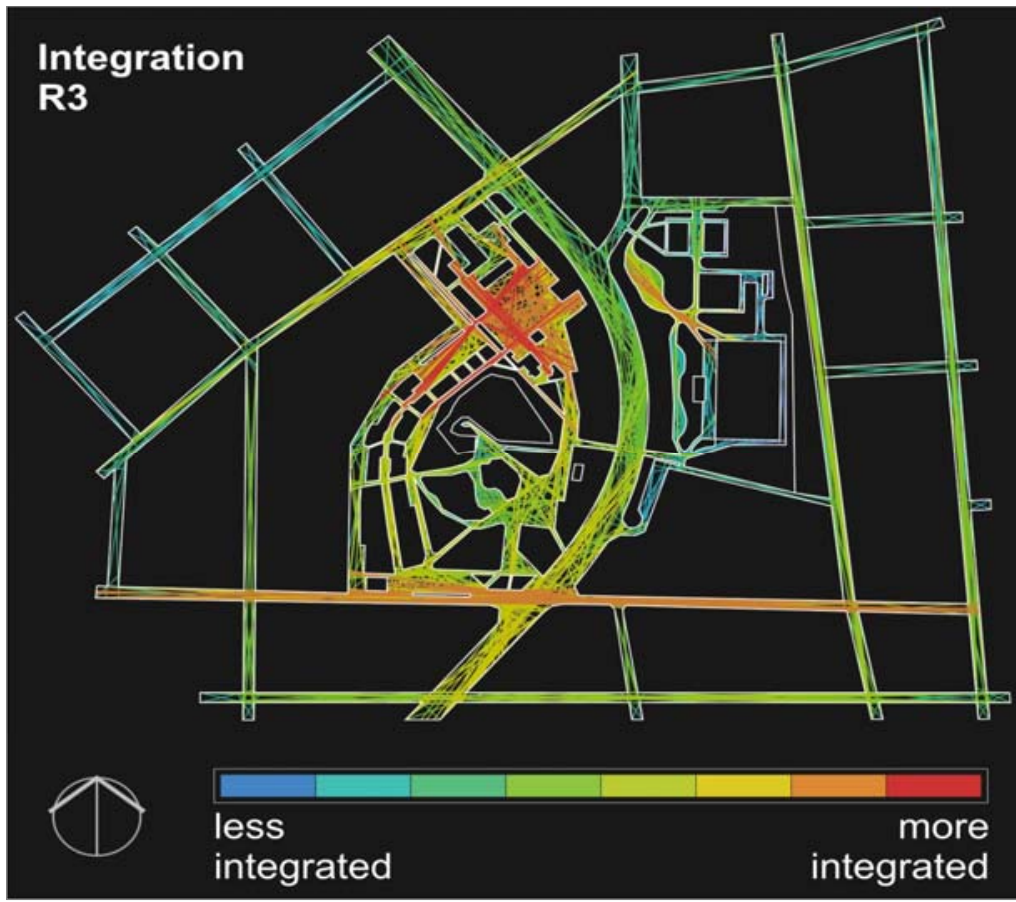

Fig. 11 All-line Integration map R3. 


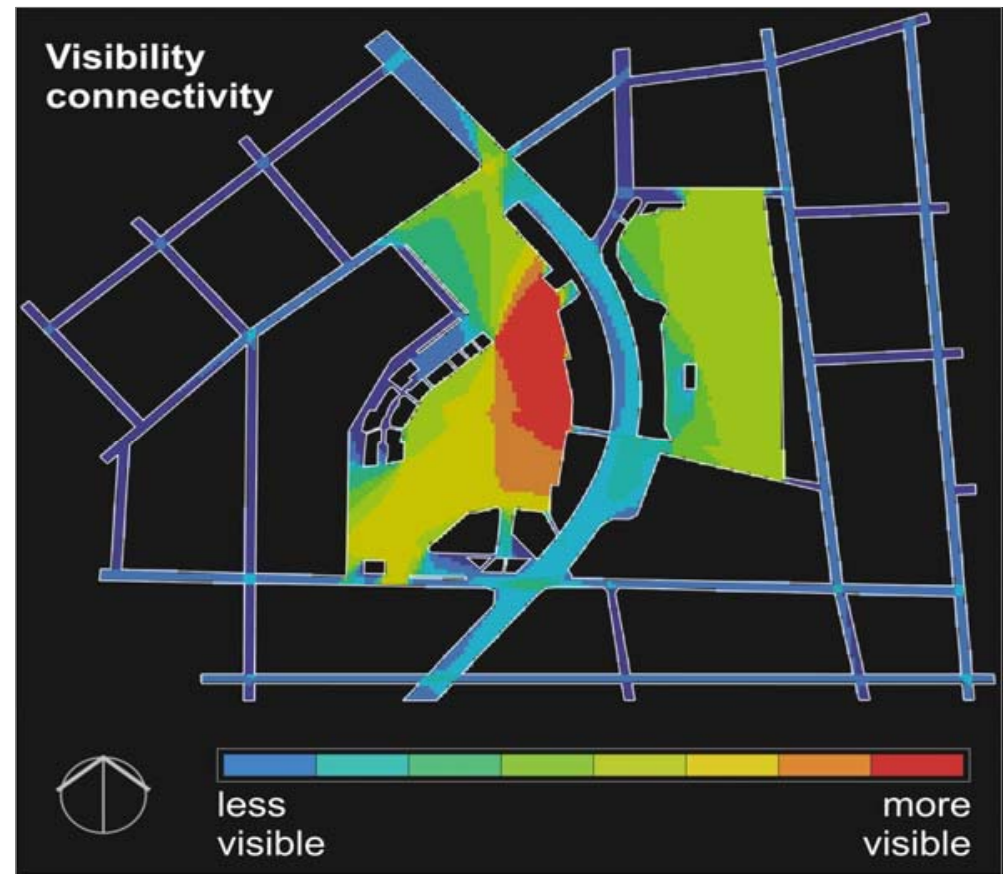

Fig. 12 Visibility map moinhos de Vento park.

Another interesting interpretation can be done regarding the difference in visibility levels between the east and west portions. A first explanation is simply the difference in size, since bigger convex areas tend to have points which are visible from a greater number of locations. Nevertheless, we can see that the west portion is considerably more visually permeable to its surrounding streets, a condition that certainly has a significant influence in the overall level of visibility. The east portion is much more closed, with few and narrow points of connection to the surroundings.

We can also see that most non-tangent streets are blocked by barriers before their visual influence can reach its interior. As we saw above, these types of axes can be powerful in fostering visual integration, and perhaps could be used as a strategy to reduce the segregation in both portions of the park.

Considering visibility inside these two portions separately, we can see that the level of visibility in the east portion is considerably high, mainly in the spaces surrounding the lake, where usually there is a higher concentration of people, this is also the chosen place to receive temporary activities/equipments such as temporary playgrounds for children or concerts.
These maps show an interesting difference regarding the location of the more integrated areas. All-line map showed it near the north border, while visibility maps (Figs. 12 and 13) placed it in the center of the park. In fact, actual appropriation of the park occurs more intensely precisely in the portion that goes from the north access down to the central area around the lake. The first possible explanation is that the all-line map took into account the system of paths, creating a large convex space near the north edge, which in turn concentrated a relatively large number of axial lines. Moreover, these lines are connected - although not directly — to 24 de Outubro Street, creating a situation of more closeness to the urban grid. Indeed, people who use this space tend to enjoy the frontier between park and city, and like to watch passers-by on the sidewalks.

The area around the lake, on the other hand, is more introverted from the permeability point of view, but has a higher visibility status. It can be seen from virtually the whole west portion and, because of that, we suspect, has a fundamental role in shaping the park identity. The fact that it is isolated both visually and physically from the surrounding streets contributes to this effect. 


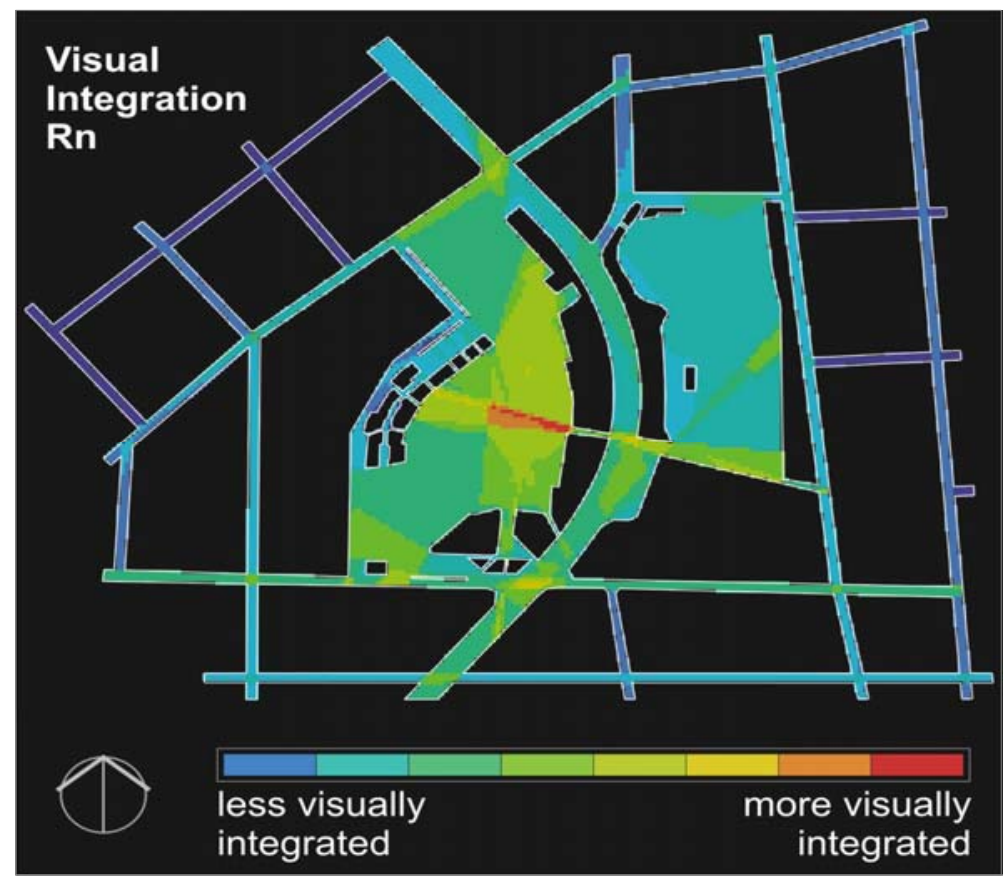

Fig. 13 Visual Integration.

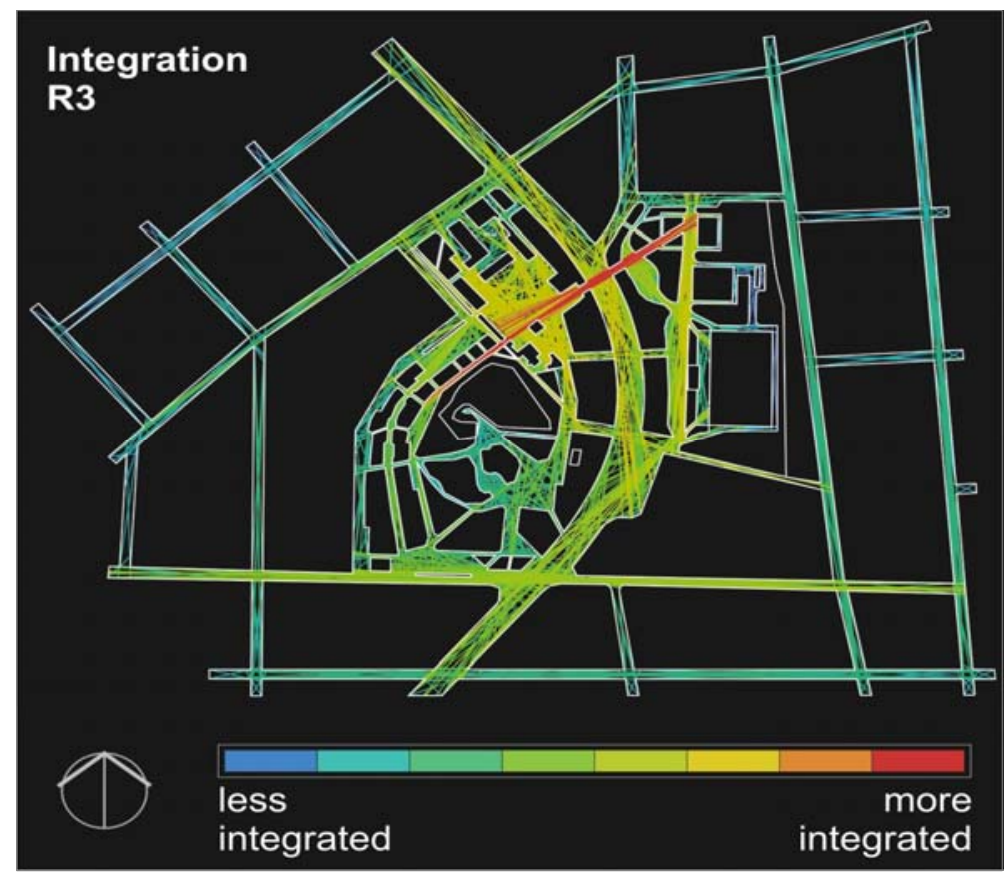

Fig. 14 R3 Integration scenario depicting more connectivity between portions.

Nevertheless, not even the central locations have visual access to the east, more segregated, portion of the park. The only possible point of visual connection is the elevated passage, this, however, is thwarted by the inclination of the ramp that practically eliminates any sight to the other side. Users, therefore, tend to associate the park only to its west portion. Most of them are not even aware about the existence of the east portion.

As a final exercise, we simulated a situation in which two aspects were changed in relation to the original configuration: first, we created permeability axes 
between the two portions, in order to foster visual and physical connectivity, then, we made minor changes in the configuration of paths at the east portion, in order to allow longer axial lines that extended in the north-south direction and created a less segmented structure. The resulting all-line map (Fig. 14) shows that these relatively simple measures could change dramatically the distribution of integration turning not only the east portion less segregated but also displacing the integration core to the connection between the two.

\section{Conclusions}

These studies show the importance of cohesion in the internal configuration of parks. Most intensely used areas are the ones that the physical configuration, on its own, showed to be the most accessible physically and visually. Internal barriers partitioning the space, if important enough, tend to influence the perception of spaces as being independent structures, as opposed to being perceived as parts of a whole. The more acute the barrier, the more intense is the segregation between parts.

The most integrated spaces are usually the most accessible ones, which in turn tend to be more intensely used. Nevertheless, physical and visual accesses have complex ways of interacting which are not fully understood so far. Architectural composition draws on these notions to create spaces and give them meaning, but the intricacies of this process remain to be more formally explained.

\section{References}

[1] S. Alex, Square design: Copresence and Exclusion in Public Spaces, São Paulo, 2008. (in Portuguese)

[2] S. Carr, M. Francis, L. Rivlin and A. M. Stone, Public Space, Cambridge University Press, Cambridge, 1995.

[3] K. Lynch, The Image of the City, The M.I.T. Press, Cambridge, 1960.

[4] B. Hillier, Space is the Machine: A Configurational Theory of Architecture (Electronic edition), London, 2007.

[5] B. Hillier and J. Hanson, The Social Logic of Space, Cambridge University Press, Cambridge, 1984.

[6] L. Vaughan, The spatial syntax of urban segregation, Progress in Planning 67 (2007) 205-294.

[7] B. Hillier, A. Turner, T. Yang and H. T. Park, Metric and topo-geometric properties of urban street networks: Some convergences, divergences and new results, in: 6th International Space Syntax Symposium, Istambul, 2007.

[8] A. Turner, M. Doxa, D. O’Sullivan and A. Penn, From isovists to visibility graphs: A methodology for the analysis of architectural space, Environment and Planning B: Planning and Design 28 (2001) 103-121.

[9] B. Hillier, A. Penn, J. Hanson, T. Grajewski and J. Xu, Natural movement: or, configuration and attraction in urban pedestrian movement, Environment \& Planning B 20 (1993) 29-66.

[10] B. Hillier, Space is the Machine, University of Cambridge, London, 1996.

[11] S. S. Macedo and F. M. G. Sakata, Parques Urbanos no Brasil, Brazilian Urban Parks, Edusp, São Paulo, 2002. 